\title{
WORKGEO: capacitação e motivação com uso de geotecnologias
}

\section{Fabio Marcelo Breunig}

Universidade Federal de Santa Maria | Brasil

fabiobreunig@gmail.com

\section{Fabiano Oliveira Fortes}

Universidade Federal de Santa Maria | Brasil

fabianofortes@gmail.com

\section{Rafaelo Balbinot}

Universidade Federal de Santa Maria | Brasil rafaelobalbinot@gmail.com

\section{Resumo}

As atividades acadêmicas em que o caráter teórico das disciplinas é elevado, muitas vezes, são massivas e pouco atraentes para os estudantes. Nesse sentido, o projeto WORKGEO foi criado e está sendo executado com o objetivo de promover a capacitação e motivação de estudantes, egressos e profissionais na área de Geotecnologias, por meio de cursos técnicos focados e de cunho prático. A metodologia consiste na avaliação das demandas, planejamento da frequência e execução de cursos. Como resultados, foram oferecidos, até o momento, cinco cursos: Geoestatística, SISVAR, ARCGIS, Modelagem de Biomassa Arbórea e QGIS. Verificou-se uma demanda superior à oferta de 150 vagas. Esse resultado mostrou a importância das atividades práticas na motivação e capacitação.

\section{Palavras-chave}

Geoestatística; ArcGIS; Q-GIS. 


\section{Introdução}

O mercado de geotecnologias está em franca expansão no Brasil e no mundo (GEWIN, 2004). A carência por levantamentos topográficos, mapeamentos temáticos (de uso do solo, estudo de bacias hidrográficas, estudos demográficos, entre outros), modelagens, sensores e produtos é em parte, reflexo da falta de profissionais qualificados e de núcleos de formação acadêmica. Deve-se mencionar que o surgimento de novos campos de atuação (Cadastro Ambiental Rural - CAR e licenciamentos de diferentes naturezas) suscita uma contínua necessidade por profissionais qualificados e uma ampla capacitação das empresas e instituições de ensino e pesquisa. Contudo, é fato que a universidade não tem conseguido capacitar os estudantes de forma a atender as expectativas do mercado de trabalho, e isso acaba por dificultar o ingresso dos recém-graduados no mercado de trabalho. Dessa forma, a constatação da necessidade de modificações no sistema de ensino - aprendizagem (ADOMSSEN et al., 2014; WALZ, 2014) requer ações afirmativas e que possam promover a integração de empresas com a academia.

A dicotomia entre aulas teóricas e práticas representa um dos maiores gargalos, tanto para a formação qualificada quanto para a promoção da motivação para a realização de cursos de graduação. Estruturas curriculares demasiadamente extensas (ementas longas, com grande sombreamento entre disciplinas ao longo de quatro ou cinco anos) e, muitas vezes, exclusivamente teóricas, promovem o distanciamento do estudante da realidade do mercado, ou mesmo, acabam por desmotivar os estudos mais avançados. Como o mercado de geotecnologias é caracterizado por uma rápida evolução, tanto de softwares quanto de hardwares, a atualização concomitante dos currículos dos cursos de graduação se torna inviável e, em sendo realizada nessa velocidade, representaria uma falta de identidade dos cursos em si. Assim, cursos de curta duração, focados em demandas localizadas e bem estabelecidas, podem promover a supressão dessa lacuna. A promoção de curso de curta duração pode ser entendida como uma função da extensão universitária, que deve ser incorporada nos cursos de graduação, como por exemplo, a Engenharia Florestal (MEC, 2001; 2004; 2006).

A extensão universitária visa a levar à comunidade os conhecimentos adquiridos e produzidos na academia, em parte, como forma de cumprir a função social da universidade. Nesse contexto, a extensão é conceituada pelo Plano Nacional de Extensão (PNE) (BRASIL, 1996; 2014) como "o processo educativo, cultural e científico que articula o Ensino e a Pesquisa de forma indissociável e viabiliza a relação transformadora entre universidade e sociedade". Ainda, 
WORKGEO: capacitação e motivação com uso de geotecnologias

esclarece que (FÓRUM DE PRÓ-REITORES DE EXTENSÃO DAS UNIVERSIDADES PÚBLICAS BRASILEIRAS, 2006, p. 1):

\begin{abstract}
A Extensão é uma via de mão dupla, com trânsito assegurado à comunidade acadêmica, que encontrará, na sociedade, a oportunidade de elaboração da práxis de um conhecimento acadêmico. No retorno à Universidade, docentes e discentes trarão um aprendizado que, submetido à reflexão teórica, será acrescido àquele conhecimento. Esse fluxo, que estabelece a troca de saberes sistematizados, acadêmico e popular, terá como consequência: a produção do conhecimento resultante do confronto com a realidade brasileira e regional; a democratização do conhecimento acadêmico e a participação efetiva da comunidade na atuação da Universidade. Além de instrumentalizadora desse processo dialético de teoria/prática, a Extensão é um trabalho interdisciplinar que favorece a visão integrada do social.
\end{abstract}

Ciente da demanda existente, o projeto de extensão universitária WORKGEO foi proposto para suprir algumas carências da formação na área de Geotecnologias e, ainda, para promover uma motivação dos estudantes e demais interessados para estudos avançados, de caráter prático. 0 projeto é caracterizado por uma estrutura de cursos de extensão voltados para estudantes, egressos, professores e profissionais da área de Geotecnologias, na perspectiva de promover a integração, capacitação e atualização nessa área e outras afins.

A proposta de cursos voltados para as ciências que fazem uso de informações espaciais vem da preocupação do isolamento de algumas unidades de ensino descentralizadas e, principalmente, dos profissionais residentes na região, os quais possuem poucas oportunidades de contato com inovações tecnológicas para o atendimento das exigências do mercado de geotecnologias. Essa atualização constante é fundamental para o aperfeiçoamento das empresas, tanto das ferramentas e das técnicas de trabalho quanto das tecnologias de planejamento, estratégia e gestão, uma vez que a reciclagem permanente possibilita a longa permanência das empresas no mercado e a manutenção de um corpo de profissionais capacitados e motivados. Além disso, o atual nível de desenvolvimento do mercado de trabalho, acirrado pelo processo competitivo global, exige o contínuo investimento no autodesenvolvimento dos profissionais. Nesse escopo, os cursos de capacitação de curta duração e tecnicamente focados representam um diferencial entre o sucesso e a manutenção de empregos e cargos.

A organização de eventos científicos e cursos consiste em uma das formas de atrair estudantes, professores, empresas e comunidade para o estudo de um determinado tema. Assim, com a realização do WORKGEO, espera-se uma motivação dos sujeitos (ministrantes, professores, profissionais da área de Geotecnologias e estudantes), de forma a incrementar suas habilidades e conhecimentos relacionados a essas tecnologias.

O projeto tem como objetivo aprofundar conhecimentos em áreas pouco exploradas, ou exploradas com enfoques distintos, por meio de profissionais renomados para atender um seleto 
WORKGEO: capacitação e motivação com uso de geotecnologias

grupo acadêmico e profissional, principalmente os egressos do Centro de Educação Superior do Norte do Rio Grande do Sul (CESNORS) da Universidade Federal de Santa Maria (UFSM), no campus de Frederico Westphalen, Rio Grande do Sul. Os cursos/eventos promovem a atualização do conhecimento técnico-científico dos profissionais, estudantes e professores de diferentes áreas de conhecimento, como Agronomia, Biologia, Engenharia Ambiental, Engenharia Florestal e Geografia, buscando se adequar às necessidades específicas dos profissionais, graduados ou não, e dos estudantes que buscam aprofundar seus conhecimentos em determinadas áreas.

Dessa forma, os cursos têm por objetivo congregar e integrar estudantes, empresas, universidades e profissionais da área de Geotecnologias que necessitam de contínua capacitação e atualização. Assim, o objetivo do WorkGEO é apresentar os avanços científicos aos estudantes, às empresas, identificar as maiores dificuldades enfrentadas pelas empresas da área e instituir um calendário de cursos com temas distintos. O evento-curso permite a integração entre universidade (estudantes), institutos de pesquisa, empresas e profissionais, levando a um novo patamar os produtos e soluções geoespaciais aplicados às Ciências Agrárias e Geociências.

Neste relato de caso, os resultados preliminares do projeto são apresentados e discutidos, visando à divulgação para a comunidade e meio acadêmico.

\section{Características gerais do projeto}

O projeto WORKGEO foi planejado para ser executado durante os anos de 2014, 2015 e 2016. Seguindo o planejamento, a frequência de dois cursos por semestre, com a possibilidade de serem oferecidos mais cursos de acordo com a disponibilidade de recursos humanos e financeiros para a execução/divulgação do curso, permite que os interessados realizem os cursos sem prejuízo às atividades rotineiras (graduação, atuação profissional, docência etc.).

Os cursos que demandam equipamentos de informática para a execução dos aplicativos de geotecnologias estão sendo conduzidos no Laboratório de Geoprocessamento e Sensoriamento Remoto (LGSR), que comporta até 30 pessoas. O LGSR foi selecionado por possuir acesso à internet, bancadas e softwares da área. Os cursos que não demandam computadores ou salas de informática são realizados nas dependências (salas de aula) da UFSM, em Frederico Westphalen.

Para fazer o curso, os candidatos devem se inscrever junto ao Diretório Acadêmico do curso de Engenharia Florestal (DAEF), de acordo com o calendário de cada curso. A divulgação dos cursos é feita mediante o uso de cartazes, comunicações pessoais, divulgação em sala de aula, site da universidade e redes sociais. 
WORKGEO: capacitação e motivação com uso de geotecnologias

Os cursos são de curta duração, com até três dias (20 horas) de amplitude. Ao início de cada período de curso, são feitas averiguações de presença. Para que o cursista receba o certificado de participação, é necessário que apresente mais de $75 \%$ de frequência. No final de cada curso, são entregues os certificados aos ministrantes, aos membros da comissão organizadora e aos cursistas que cumpriram com a frequência mínima. Os certificados são registrados em livro/ata da Secretaria Unificada dos Departamentos (SUDEP), no CESNORS/UFSM.

\section{Metodologia dos cursos ou eventos}

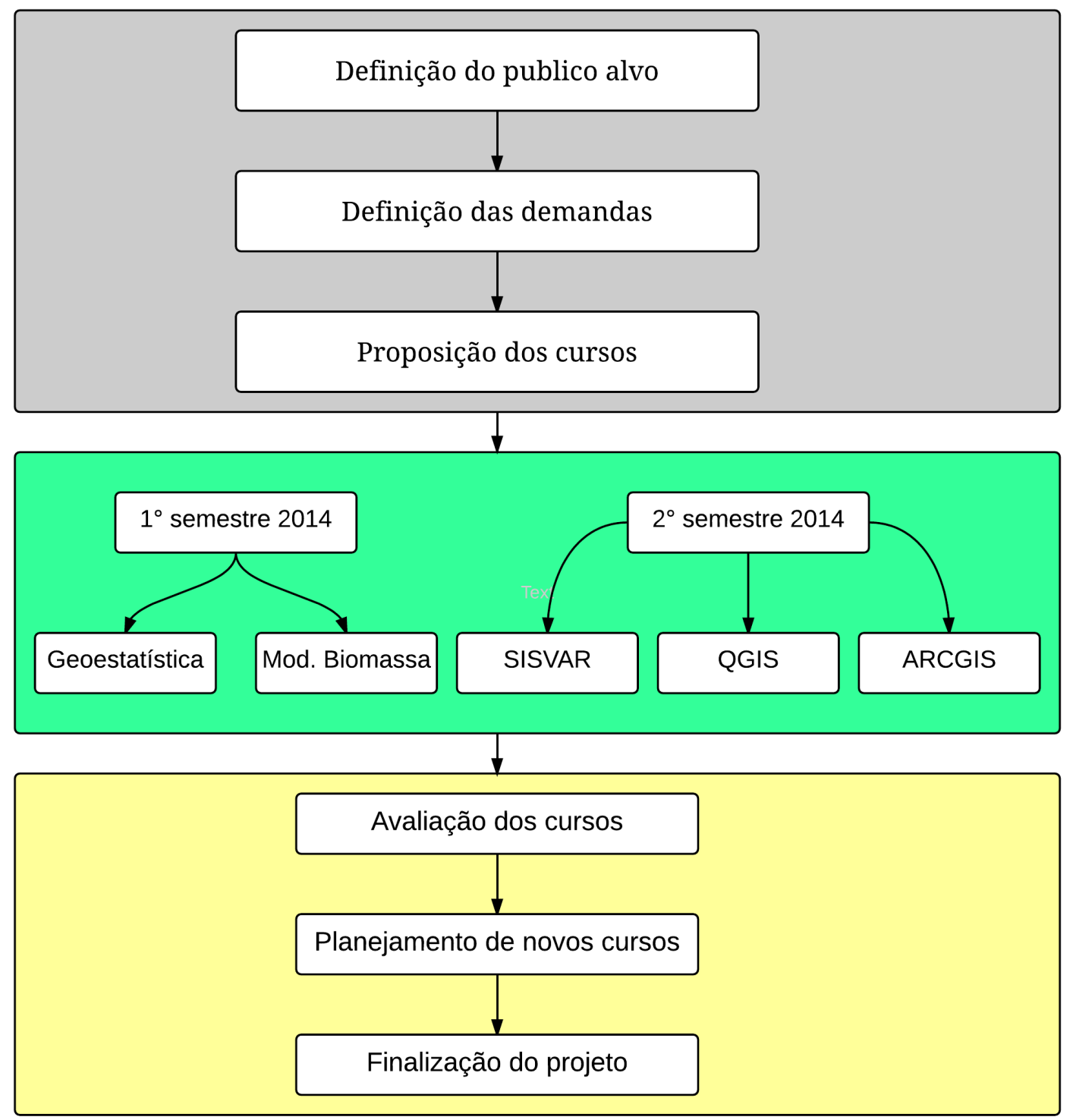

Ilustração 1: Fluxograma ilustrando as principais etapas do projeto WORKGEO, considerando os cursos realizados no ano de 2014.ARCGIS é uma marca registrada da empresa ESRI.

Fonte: Elaboração dos autores 
WORKGEO: capacitação e motivação com uso de geotecnologias

O fluxograma apresentado na Error! Reference source not found. mostra as principais etapas da execução do projeto WORKGEO. O projeto está em execução no campus de Frederico Westphalen, Rio Grande do Sul, da Universidade Federal de Santa Maria. Para a sua realização, conta com o apoio do Departamento de Engenharia Florestal (DEF) (localização indicada na Ilustração 2), tendo por público-alvo os estudantes de todos os semestres dos cursos de Engenharia Florestal, Engenharia Ambiental e Sanitária e Agronomia, além de professores da universidade que fazem uso das ferramentas de geotecnologia e de egressos e profissionais que atuam nessa área.

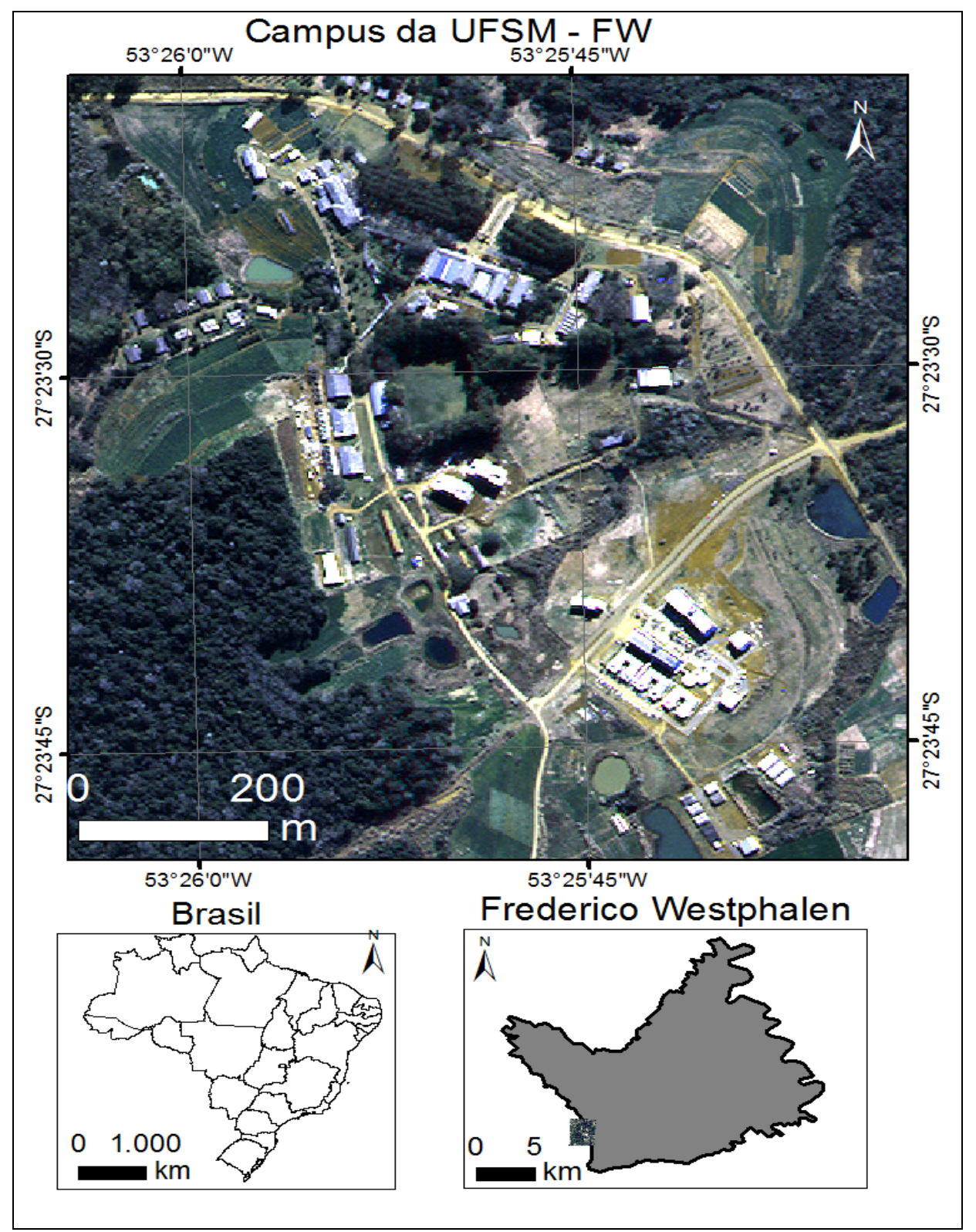

Ilustração 2: Localização da área onde o projeto WORKGEO está sendo executado. Composição colorida tipo cor-verdadeira contrastada, de novembro de 2011, adquirida pelo satélite Worldview-2.Malha dos estados e municipal foi adquirida do Instituto Brasileiro de Geografia e Estatística (IBGE).

Fonte: Elaboração dos autores 
WORKGEO: capacitação e motivação com uso de geotecnologias

Dada a definição do público-alvo, partiu-se para o estabelecimento das demandas, com foco na capacitação e motivação dos estudantes do campus, para a área de Geotecnologias. Assim, foram definidos os cursos oferecidos no primeiro e no segundo semestres de 2014. Essa definição, ainda, considerou a disponibilidade de ministrantes e de recursos para viabilizar a logística de cada curso. A participação de professores, profissionais e egressos foi incentivada, mediante a divulgação para listas de e-mails, redes sociais e contatos diretos.

Considerando a dinâmica dos cursos propriamente dita, eles consistem em palestras/aulas, formalizadas por meio de apresentações em projetores de multimídia, com enfoque aos conceitos e definições terminológicas, à evolução do estado da arte dos temas e das principais literaturas especializadas, bem como às aplicações práticas e exemplificações focadas à área de Ciências Agrárias/Florestais e Geociências.

Durante os cursos, os participantes são convidados ao diálogo, visando à mitigação de dúvidas e ao aprofundamento das discussões sobre casos práticos por eles vivenciados, principalmente, com a aplicação de programas computacionais específicos para os temas abordados.

Para a execução prática dos cursos, é recomendado que os participantes tenham computadores pessoais para as atividades, para a repetição das tarefas fora do período do curso e para a resolução de exercícios. Aos participantes sem computador, o LGSR disponibiliza um equipamento para uso durante o curso.

Às atividades práticas, que fazem uso de softwares de processamento de dados, nos cursos, são utilizadas bases de dados reais, obtidas em inventários florestais, estudos ambientais e estimativas clássicas da literatura. As questões referentes às coletas de dados até os produtos finais dos processamentos são exaustivamente abordadas. Em alguns casos, os aplicativos utilizados não são de acesso gratuito, assim, são usadas versões demonstrativas.

Concomitantemente às aulas práticas, tópicos teóricos são abordados, em que as definições, os objetivos e as justificativas das técnicas são estudados, simulando situações específicas e suas possíveis soluções.

Após cada curso, são feitos questionamentos aos participantes sobre sugestões de cursos e, quando confirmados, são informadas a data, nome e local do próximo evento do projeto.

Para avaliar o resultado, são feitas indagações informais para os participantes, por parte da comissão organizadora. Os impactos de longo prazo não estão sendo avaliados neste primeiro ano de projeto. Essa metodologia foi adotada para reduzir o tempo entre a realização do questionário (muitas vezes exaustivo e ineficaz) e a adoção de medidas de correção.

\section{Resultados parciais do Projeto de Extensão}




\subsection{Resultados objetivos do projeto - ano de 2014}

O projeto WORKGEO está registrado na UFSM, desde 2014, como projeto de extensão. Até o momento, foram oferecidos cinco cursos de 20 horas, sendo dois no primeiro semestre de 2014 e três no segundo semestre desse mesmo ano. Os cursos oferecidos e algumas características são apresentados na Tabela 1. Os dois primeiros foram realizados no primeiro semestre de 2014, sendo ministrados por doutorandos da Universidade Federal do Paraná (UFPR). O curso de SISVAR (FERREIRA et al., 2000; 2004; 2011) foi conduzido por um mestrando do Programa de Pós-Graduação em Ciências Florestais da UFSM. O curso de QGIS (SHERMAN et al., 2014) foi ministrado por um doutorando de Geografia da Universidade Federal de Santa Catarina (UFSC) e o curso de ARCGIS $\odot$ (ESRI inc., 2014) por um mestrando de Geografia do Programa de Pós-Graduação em Geografia da UFSM. O curso de geoestatística foi efetuado com base no aplicativo demonstrativo GS+ ${ }^{\odot}$ (GAMMA DESIGN, 2014) e mostrou-se muito oportuno para as aplicações dos cursistas.

Após a abertura oficial das inscrições, em muitos casos, as vagas disponibilizadas foram esgotadas no primeiro dia, com lista de espera. Esse fato comprova a demanda por esse tipo de capacitação.

As atividades práticas desenvolvidas durante o curso de SISVAR, no LGSR, são apresentadas na Ilustração 3 (a seguir) No momento, os cursistas estavam operando os aplicativos GS+๑ (GAMMA DESIGN, 2014). As atividades práticas ilustradas foram precedidas e acompanhadas de explicações teóricas e demonstrações numéricas em quadro.

Para todos os que participaram do curso, desde a criação, organização, cursistas e ministrantes, são fornecidos certificados registrados pelo Departamento de Engenharia Florestal (DEF) do campus de Frederico Westphalen da UFSM. Na Ilustração 4 são apresentados frente e o verso do certificado fornecido ao ministrante do curso de ARCGIS® (ESRI inc., 2014).

Tabela 1: Dados dos cursos realizados até o momento no escopo do projeto WORKGEO - ano de 2014.

\begin{tabular}{|c|c|c|}
\hline Nome do curso & Vagas & Data de realização \\
\hline Geoestatística com GS+ & 25 & 28 a 30 de maio de 2014 \\
\hline Modelagem de Biomassa Arbórea & 40 & 28 a 30 de maio de 2014 \\
\hline SISVAR - Estatística & 25 & 11 a 13 de setembro de 2014 \\
\hline QGIS aplicado às Ciências Agrárias e Ambientais & 30 & 6 a 8 de outubro de 2014 \\
\hline ARCGIS aplicado às Ciências Agrárias e Ambientais & 30 & 12 a 14 de novembro de 2014 \\
\hline Total & 150 & \\
\hline
\end{tabular}


WORKGEO: capacitação e motivação com uso de geotecnologias

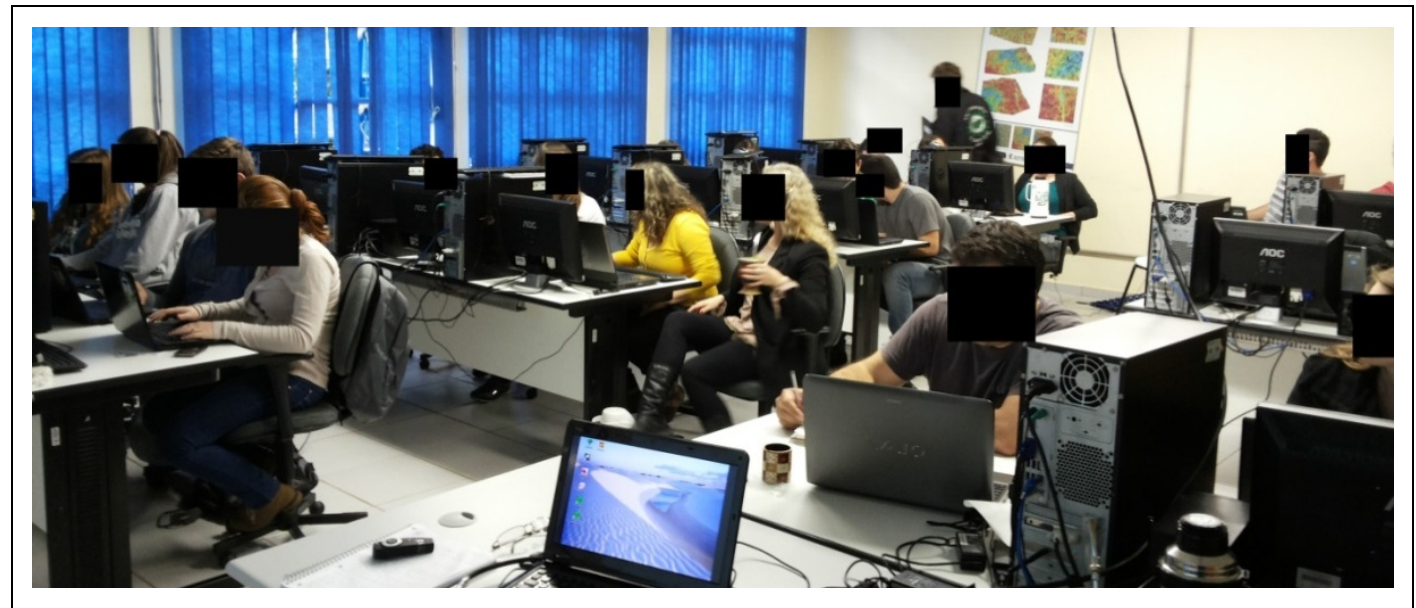

Ilustração 3: Registro no Laboratório de Geoprocessamento e Sensoriamento Remoto (LGSR) durante o curso de GS+๑ (GAMMA DESIGN, 2014), 11 set. 2014.

Fonte: Os autores

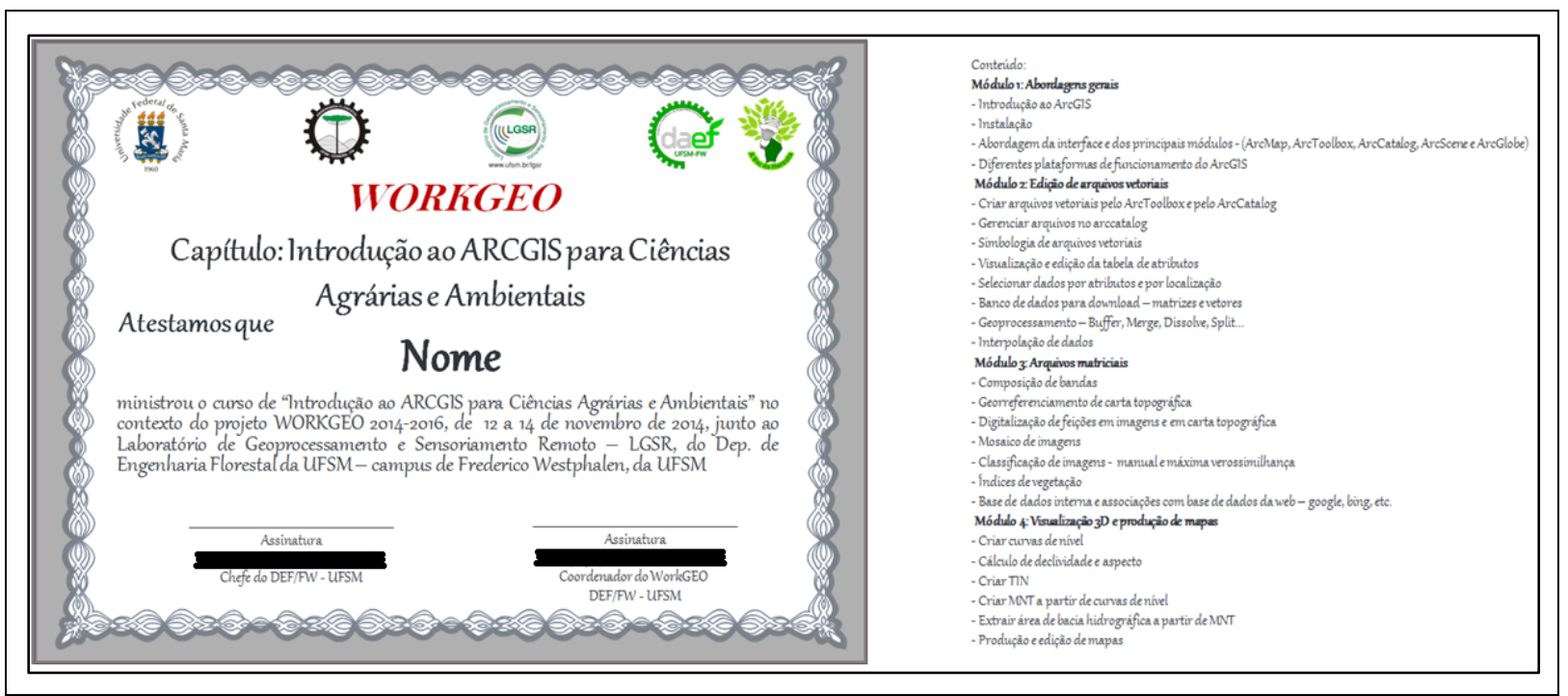

Ilustração 4: Modelo de certificado ao ministrante do curso (frente e verso) com os conteúdos abordados. Fonte: Os autores

As atividades práticas, baseadas no uso de softwares de geotecnologia e estatística, conseguiram trazer os participantes para o cotidiano de sua atuação profissional, fazendo a interação entre palestrantes e ouvintes aumentar.

\subsection{Resultados indiretos}

Uma das contribuições indiretas do projeto de extensão WORKGEO consiste na inserção de egressos do próprio campus para ministrar cursos. Com essa possibilidade, os egressos, que em sua maioria estão inseridos em programas de pós-graduação (mestrado e doutorado), têm a 
WORKGEO: capacitação e motivação com uso de geotecnologias

possibilidade de um contato direto com um dos principais campos de atuação da academia: transmissão do conhecimento (professor). Esses novos ministrantes, normalmente, possuem uma ampla experiência em softwares específicos, de acordo com o campo de pesquisa a que se dedicam no mestrado ou doutorado. Assim, são os convidados "ideais" para fazer a ponte entre a pesquisa de ponta da pós-graduação e os estudantes de graduação e profissionais (egressos, professores e profissionais da área de Geotecnologia).

O contato dos estudantes de graduação com egressos, profissionais e pós-graduandos foi muito importante, porque retratou a importância da área de Geotecnologias e de seu uso no mercado de trabalho e na vida acadêmica. Esse fato vai ao encontro da demanda de alguns cursos de graduação por atividades de motivação, a fim de reduzir a evasão e de aproximar a academia do mercado de trabalho.

A utilização de cursos de curta duração para conhecimento, aperfeiçoamento e aprimoramento, tanto na graduação quanto na pós-graduação, mostrou-se uma metodologia válida para unidades descentralizadas, principalmente pela busca de profissionais em diferentes áreas de conhecimento. Os cursos de extensão foram concluídos com êxito e, nos próximos semestres (2015-2016), espera-se realizar mais dois cursos.

\subsection{Avaliações pelos participantes/cursistas}

Em uma avaliação informal feita com participantes dos cursos, durante e logo após sua execução, foram constatados um alto grau de satisfação dos envolvidos e o reconhecimento da importância desse tipo de capacitação para formar e motivar os estudantes, principalmente do curso de Engenharia Florestal. A mesma impressão foi identificada durante os intervalos (coffee break), em questionamentos feitos pela comissão organizadora aos cursistas. Outro ponto de destaque refere-se à intensão de participarem de outros cursos a serem oferecidos durante os anos de 2015 e 2016.

\subsection{Perspectivas futuras}

Como o projeto WORKGEO ainda está em andamento, espera-se que o número de pessoas atendidas seja dobrado, à medida que os novos cursos sejam oferecidos. Entre os novos eventos que estão planejados, destacam-se os cursos de "LiDAR (Light Detection And Ranging), aplicado as Ciências Florestais", de "Introdução ao software ENVI®(EXCELIS VIS, 2014) - 
WORKGEO: capacitação e motivação com uso de geotecnologias

soluções de processamento de imagens", de "GeoWeb aplicada (Plataforma Google ${ }^{\odot}$, ArcGIS Web, SPRING Web)", de "Sensoriamento remoto hiperespectral", de "Monitoramento florestal em regiões tropicais", de "Sensoriamento Remoto Ativo - PolSAR-Pro", "Geo e CAR", de “Elaboração de gráficos para produção acadêmica (Origin` ${ }^{\circledR}$ - OriginLab Corporation, 2010)” de "Programação aplicada", entre outros.

\section{Considerações finais}

No total, o projeto disponibilizou, até o momento, 150 vagas, distribuídas em cinco cursos, executados no primeiro (dois cursos) e segundo semestres (três cursos) de 2014, no campus de Frederico Westphalen da UFSM.

O projeto proposto está atingindo as expectativas iniciais e transcorrendo de acordo com o planejamento, de modo que, no final dos cursos, os alunos estavam familiarizados com os conceitos e as definições dos softwares e os modelos estudados.

Os cursos colocaram os participantes em contato com novas áreas de conhecimento e aplicações das geotecnologias na área florestal, agronômica e ambiental. Uma grande quantidade de problemas foi solucionada, por todos os participantes dos cursos.

Os alunos mostraram estar aptos a operar os principais softwares de processamento de dados aplicados aos temas abordados nos diversos cursos.

No final do curso, felizmente, o número de perguntas foi muito maior que o número de respostas. Isso mostra que o curso atingiu o objetivo de motivar e capacitar os participantes, que passaram a vislumbrar novas possibilidades para suas atividades acadêmicas ou profissionais, resultando em um novo grupo de questões a serem respondidas.

\section{Referências}

ADOMSSEN, Maik et al. Emerging areas in research on higher education for sustainable development - Management education, sustainable consumption and perspectives from Central and Eastern Europe. Journal of Cleaner Production v. 62, p. 1-7.

BRASIL (Presidência da República - Casa Civil - Subchefia para Assuntos Jurídicos). Lei no 9.394, de 20 de dezembro de 1996: Estabelece as Diretrizes e Bases da Educação Nacional. Brasília, 20 de dezembro de 1996; 175으 da Independência e 108o da República. Documento online. 1996. Disponível em: <http://www.planalto.gov.br/ccivil_03/leis/19394.htm>. Acesso em: $11 \mathrm{dez}$. 2014.

BRASIL. (Presidência da República - Casa Civil - Subchefia para Assuntos Jurídicos). LEI № 13.005, DE 25 JUNHO DE 2014. Aprova o Plano Nacional de Educação PNE e dá outras providências. Online. 2014. Disponível em: <http://pne.mec.gov.br/>. Acesso em: 14 dez. 2014. 
WORKGEO: capacitação e motivação com uso de geotecnologias

ESRI Inc. ARCGIS Demonstrativo. Disponível em: <www.arcgis.com/>. Acesso em: 8 fev. 2015.

EXCELIS VIS. ENVI - Exelis Visual Information Solutions. V. 5.1. Boulder CO. 2014. Disponível em: $<$ www.exelisvis.com/envi/>. Acesso em 8 fev. 2015.

FERREIRA, D.F. Análises estatísticas por meio do Sisvar para Windows versão 4.0. In... 45a Reunião Anual da Região Brasileira da Sociedade Internacional de Biometria. UFSCar, São Carlos, SP, Julho de 2000. p. 255-258.

FERREIRA, DANIEL FURTADO. SISVAR: a computer statistical analysis system. Ciência e Agrotecnologia (UFLA), v. 35, n.6, p. 1039-1042, 2011.

FERREIRA, DANIEL FURTADO. SISVAR: um programa para análises e ensino de estatística. Revista Symposium (Lavras), v. 6, p. 36-41, 2008.

FÓRUM DE PRO-REITORES DE EXTENSÃO DAS UNIVERSIDADES PÚBLICAS BRASILEIRAS. Plano nacional de extensão universitária. Disponível em: $<$ http://www.renex.org.br/documentos/Colecao-Extensao-Universitaria/01-PlanoNacionalExtensao/Plano-nacional-de-extensao-universitaria-editado.pdf $>$. Acesso em: 30 jan. 2015.

GAMMA DESIGN. GS+:Geostatistics for the Environmental Sciences. 2014. Disponível em: <http://www.gammadesign.com/>. Acesso em: 8 fev. 2015.

GEWIN, Virginia. Mapping opportunities. Nature. v. 427, n. 6972, p. 376-377 , 22 jan. 2004.

MINISTÉRIO DA EDUCAÇÃO (MEC). Conselho Nacional de Educação - Câmara de Educação Superior. Resolução no 3, de 2 de fevereiro de 2006: Institui as Diretrizes Curriculares Nacionais para o curso de graduação em Engenharia Florestal e dá outras providências. Online. 2006. Disponível em: <http://portal.mec.gov.br/cne/arquivos/pdf/rces03_06.pdf>. Acesso em 11 de dezembro de 2014.

MINISTÉRIO DA EDUCAÇÃO (MEC). Conselho Nacional de Educação. Câmara de Educação Superior. Parecer no: CNE/CES 583/2001 - Orientação para as diretrizes curriculares dos cursos de graduação. Processo $\mathrm{n}^{\circ}$ : 23001.000141/2001-15. Documento disponível online. 2001. Disponível em: <http://portal.mec.gov.br/sesu/arquivos/pdf/58301orientacoes.pdf>. Acesso em 11 dez. 2014.

MINISTÉRIO DA EDUCAÇÃO/SECRETARIA DE ENSINO SUPERIOR. CONSELHO NACIONAL DE EDUCAÇÃO (MEC). Diretrizes Curriculares do Curso de Engenharia Florestal. 2004. Disponível em: <http://www.mec.gov.br/sesu/diretrizes.html>. Acesso em 20 fev. 2015.

ORIGINLAB CORPORATION. Origin. Northampton, MA - USA. 2010. Disponível em: <www.originlab.com>. Acesso em: 20 fev. 2015.

SHERMAN GE, SUTTON T, BLAZEK R, HOLL S, DASSAU O, MORELY B, MITCHELL T AND LUTHMAN L. Quantum GIS User Guide - Version 2.4 "Chuchiag". 2014. Disponível em: <www.qgis.org/>. Acesso em: 17 jan. 2015.

UNIVERSIDADE FEDERAL DE SANTA MARIA (USFM). Plano de Desenvolvimento Institucional - PDI: 2011-2015. Santa Maria: UFSM. Online. Santa Maria, RS, abril de 2011. 
WORKGEO: capacitação e motivação com uso de geotecnologias

Disponível em: <http://site.ufsm.br/arquivos/uploaded/arquivos/be1eb2e0-4629-442e-b1af79c251e3ac83.pdf>. Acesso em: 11 dez. 2014.

WALS, Arjen E J. Sustainability in higher education in the context of the un DESD: A review of learning and institutionalization processes. Journal of Cleaner Production v. 62, p. 8-15.

\section{WORKGEO: capacitation and motivation with use of geotechnology}

\begin{abstract}
The theoretical nature of courses is high in the academic activities and so, is often massive and unattractive to students. In this sense, the WORKGEO project was created and is being implemented in order to promote the training and motivation of students, graduates and professionals regarding geotechnology area through focused technical courses with practical nature. The methodology is based on the demands assessment, frequency planning and implementing of the courses. As results, have been offered so far five courses: Geostatistics, SISVAR, ArcGIS, Arboreal Biomass Modeling and QGIS. There was a demand exceeding supply of 150 vacancies. This result showed the importance of practical activities in motivating and training.
\end{abstract}

\section{Keywords}

Geostatístics; ArcGIS; Q-GIS.

Original submetido em: 19 mar. 2015

Aceito para publicação em: 12 maio 2015

\section{WORKGEO: capacitación y motivación con el uso de geotecnología}

\begin{abstract}
Resumen
Las actividades académicas en que el carácter teórico de los cursos es alta, muchas veces son masivas y poco atractivas para los estudiantes. En ese sentido, el proyecto WORKGEO fue creado y está siendo ejecutado con el objetivo de promover la capacitación y motivación de estudiantes, egresados y profesionales en el área de geotecnologías, a través de cursos técnicos enfocados y de carácter práctico. La metodología utilizada se fundamenta en la evaluación de demandas, planificación de la frecuencia y ejecución de cursos. Como resultados, fueron ofrecidos hasta el momento cinco cursos: Geoestatística, SISVAR, ARCGIS, Modelado de Biomasa Arbórea e QGIS. Se verificó una demanda superior a la oferta de 150 plazas. Ese resultado mostró la importancia de las actividades prácticas en la motivación y capacitación.
\end{abstract}

Palabras clave

Geoestatística; ArcGIS; Q-GIS.

Sobre os autores:

\section{Fabio Marcelo Breunig}

Doutor em Sensoriamento Remoto pelo INPE. Professor do Departamento de Engenharia Florestal da Universidade Federal de Santa Maria (UFSM), Campus Frederico Westphalen, e no Programa de Pós-Graduação em Geografia. 
WORKGEO: capacitação e motivação com uso de geotecnologias

\section{Fabiano Oliveira Fortes}

Professor de Departamento de Engenharia Florestal da Universidade Federal de Santa Maria (UFSM), Campus Frederico Westphalen.

\section{Rafaelo Balbinot}

Professor de Departamento de Engenharia Florestal da Universidade Federal de Santa Maria (UFSM), Campus Frederico Westphalen. 